\title{
Conversas sobre formarfazera nutrição: as vivências e percursos da Liga de Segurança Alimentar e Nutricional
}

Olívia Maria Ferreira Schneider ${ }^{(a)}$ Alden dos Santos Neves ${ }^{(b)}$

\section{Começando as conversas}

O eixo motivador deste texto foram conversas diversas presenciais, por e-mails e também nas redes sociais. Os diálogos giravam sobre: formação em nutrição, modos de fazer docente, contexto da segurança alimentar e nutricional, promoção do direito humano à alimentação adequada, e limites da teoriaprática. As narrativas delineavam opiniões, percursos, possibilidades, sonhos, caminhos possíveis de fazer diferente, gerando as ideias e processo em/de construção.

Optamos por continuar narrando, pois essa forma diferenciada de falarescrever revelaria as vivências e a realidade.

Pesquisamos outros modos de fazer da escrita e encontramos eco nas ideias e escritos de Oliveira ${ }^{1}$. A autora mostra que é possível romancizar a ciência e valorizar outros conhecimentos construídos em várias tessituras, formas, cores e movimentos. Então, mãos unidas e corações em sintonia para iniciar a construção literária.

Esta narrativa fala de construção, tece fios numa rede de conhecimentos sobre formação em nutrição e segurança alimentar e nutricional. Vivências que inspiram e emocionam. Optamos por uma expressão textual que valoriza as práticas educativas, suas inter-relações, os sentimentos, as dificuldades, os avanços e atropelos, os desafios, e também as possibilidades.

A narrativa estimula novos voos e nos remetemos a Oliveira ${ }^{1}$ utilizando a falaescrita de Maria da Conceição Almeida²:

É saudável projetarmos espaços de fuga para além das muralhas conceituais, teóricas e metodológicas que interditam a visão de horizontes maiores, mais plenos, perigosos, criativos; mais movediços, incertos, provocativos, desavergonhados. ${ }^{2}$

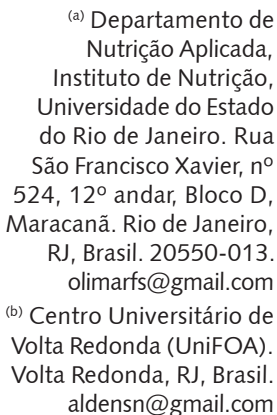

Nutriçamento de Instituto de Nutrição, Universidade do Estado do Rio de Janeiro. Rua São Francisco Xavier, n Aloco D RJ, Brasil. 20550-013. olimarfs@gmail.com Centro Universitário de Volta Redonda (UniFOA)
Volta Redonda, RJ, Brasil aldensn@gmail.com 


\title{
Segurança alimentar e nutricional: fios para as redes de saberes e modos de formarfazer a nutrição
}

O campo da Segurança Alimentar e Nutricional (SAN) passou por complexa expansão em nosso país e, hoje, seus múltiplos saberes ampliam as discussões do tema alimentação e nutrição. Um exemplo de integração de saberes é o conceito descrito no relatório da II Conferência Nacional de Segurança Alimentar e Nutricional ocorrida em 2004 em Pernambuco:

\author{
Segurança Alimentar e Nutricional (SAN) é a realização do direito de todos ao acesso regular \\ e permanente a alimentos de qualidade, em quantidade suficiente, sem comprometer o \\ acesso a outras necessidades essenciais, tendo como base práticas alimentares promotoras \\ de saúde, que respeitem a diversidade cultural e que sejam social, econômica e \\ ambientalmente sustentáveis. ${ }^{3}$
}

Inúmeros aspectos deste conceito configuram-se ao longo da última década, estimulam debates, e adquirem relevância política gerando implementação de políticas públicas. Estes debates se deram a partir de intensos diálogos, tensões, pressões, participação, e negociações entre organizações da sociedade civil e governo.

Este percurso nos remete à noção de rede que ultrapassa a noção da disciplinaridade e da setorialidade, tem outra tessitura, promove diálogo, o pensar complexo, valoriza a prática social e, assim, desvela-se o olhar para os espaços de experiências que não só os oficiais ${ }^{4}$.

Os diferentes aspectos são os fios teóricos que se articulam na rede, no caso de SAN, entrecruzando-se. Sabemos que, até hoje, a capacidade de articulação entre eles é um grande desafio.

A rede tecida pelos saberes e atores, sob um olhar menos atento, pode revelar um conjunto de conhecimentos isolados e autônomos, com restrição dialógica entre eles. Esta percepção se dá devido à visão tradicional e hierarquizada do funcionamento de programas e ações, onde diversos setores têm funções nos campos: técnico, político, orçamentário, de gestão.

Numa transição estratégica, a construção dos nós integradores destes saberes contribuiria para criar um sistema de integração, tanto para o monitoramento como para articular orçamento e gestão, e na opinião de Burlandy ${ }^{5}$, reordenar processos de trabalho, tanto quanto transpassar " as dificuldades para a ação integrada, tais como as diferenças de valores, e ideias, a redistribuição de recursos financeiros, humanos e políticos, tempo". Ressalta a autora que favoreceria o diálogo entre os níveis de governo.

Uma vitória seria propiciar diálogo essencial entre diversos programas e, com os saberes locais, tecer um "saber coletivo múltiplo", na clareza de que o espaço da vida cotidiana é "espaço/tempo de produção de conhecimentos válidos e necessários" 4 .

Para conversas e modos de fazer a SAN renovados sob a égide da interação, é preciso aproximar parceiros de múltiplos cenários. Provoca-se o movimento de tessitura de projetos de aprenderensinar SAN. Tecemos saberes mais técnicos necessários ao empoderamento dos atores, e também saberes singulares. Nessa pluralidade se constroem modos de fazer a SAN mais interativos no nível estadual e municipal.

Alguns desses saberes são revisitados nos espaços de conhecimento, intra ou extra-universitários. Exemplificamos alguns deles: a produção de alimentos e seus modelos, o acesso, as características de seu consumo, a utilização biológica e a qualidade destes; suas implicações econômicas, culturais e sociais; a garantia do direito humano à alimentação adequada; as implicações nutricionais no âmbito da saúde; programas de alimentação em escala nacional; programas de transferência de renda; a soberania alimentar.

Esta multidimensionalidade estimula o debate acadêmico, entre estudantes e professores dos cursos de graduação em Nutrição e geralmente estes conteúdos estão inseridos nas disciplinas que vinculam a Nutrição e a Saúde Pública.

Esses debates valorizam aspectos teóricos, destacam a trajetória do tema, sua evolução, inter-relações, valorização no cenário nacional, percurso de elaboração de políticas públicas, contextualizando a SAN. 
Em comparação às conversas teóricas, as vivências práticas no/do tema deixam a desejar. Perde-se a oportunidade de entrar na rede, de compartilhar outro/seus modos de estar no mundo, de interagir com outras linguagens, de trilhar rumos para a participação ativa e cidadã. Articular saberes e apreender a realidade ficam desprestigiados, reforçando a famosa dicotomia teoria/prática.

Algumas pistas nos levam aos motivos que reforçam esta dicotomia. A compartimentalização do saber separa-o em "caixinhas", acessadas quando o discente entra em contato com cada um separadamente. Este processo geralmente é conduzido por um docente, reconhecido como o "dono das caixinhas". Outro aspecto seria que o espaço social é uma estrutura complexa, interdisciplinar, múltiplo, dinâmico e imprevisível, com diversas linguagens podendo representar muralhas para as ações acadêmicas. Esta incerteza provoca desestabilização à organização previsível dos modos de fazer de ensinar/aprender, graficamente separados por uma barra.

Remetendo-nos a Gallo ${ }^{6}$, neste contexto fica difícil otimizar a formação do aluno, sobretudo na formação em SAN que não acontecerá somente pela "assimilação de discursos". A formação deste aluno, para que possa "assumir posturas de liberdade, respeito, responsabilidade", "suscita interação com espaços que rompem as fronteiras das salas de aula tramando redes de saberes que possibilitam novos territórios". Segundo o autor, "qualquer espaço social pode ser o lugar do aprendizado, do acesso aos saberes e de sua circulação e partilha" 6 e podemos afirmar que fora da escola/universidade também se aprende.

Os diálogos acadêmicos nem sempre propiciam outras formas de saber e de estar, nem tampouco situar questões políticas, sociais, culturais e econômicas. Isto pode delinear o modo como certos pesquisadores valorizam os estudos científicos e suas próprias concepções de ciência. Segundo Santos, Meneses e Nunes ${ }^{7}$ a atitude de ignorar a produção do saber local reafirma a postura de considerá-lo como um não-saber ou como um saber subalterno. Cria-se, então, uma divisão hierárquica entre conhecimento técnico incluindo modelos, tecnologias, respostas técnicas, e as práticas desenvolvidas nas comunidades.

A abertura para uma relação entre professores e alunos que promova movimentos e diálogos questionadores, que renove o debate, recupere diferentes saberes, que envolva outros atores, gera a perspectiva de participação "mais alargada e informada" 7 . Pode-se ir e vir, trazendo parceiros de percurso para o cenário de aprendizagem, revelando-se condições diversas e reais e também aspirações concretas.

Rompe-se com as amarras dos conteúdos programáticos das disciplinas e enredam-se alunos e professores nos fios das redes de conhecimentos tecidas. Sob esta ótica, o ato de ensinaraprender é colocado numa nova situação menos técnica, menos classificatória, menos modelada, mas nem por isso menos profunda, tramando novos modos de fazer a nutrição e a segurança alimentar e nutricional.

E este tema complexo provoca questionamentos, dúvidas e incertezas, mas gera possibilidades, tecendo outras redes com os autores que nos referenciam. É no campo instável onde as certezas são questionadas que nos defrontamos com as diferenças, as deficiências e as dificuldades da sociedade em resolver seus problemas essenciais, como a fome e a pobreza extrema. É neste estado de desconforto onde somos estimulados a perceber os muros que se constroem e que acabam por conter o diálogo necessário e as vivências de articulação. Este cenário revela as violações dos direitos humanos e mexe e remexe com outros sentidos em nós e nos alunos, sensíveis em diversas escalas ao que os move.

Sente-se o tamanho do desafio: instigar a reflexão conjunta que se entrelace nas práticas sociais, interagindo, e acrescentando algo significativo ao cotidiano da vida das pessoas.

Este processo não se dá sozinho. É compartilhado, solidário, interativo, sempre investigativo, investe nas descobertas, nas experiências, nas dúvidas, nas incertezas. É neste espaço de formação que no dizer de Alves ${ }^{4}$ : "[...] cada professor é chamado a desempenhar simultaneamente, o papel de formador e formando, em redes coletivas de trabalho, nas quais também outros sujeitos são chamados de diferentes e múltiplos espaços para ajudar nessa formação".

Compactuamos com a ideias de Santos, Meneses e Nunes ${ }^{7}$ sobre as experiências de construção, processos de produção de práticas que se colocam em interação em maneiras de fazer ou de competências adquiridas, com o intuito de criação de algo que antes não existia, adquirindo novas propriedades, assumindo um diálogo possível com outras formas de saber. Reconhecemos que esta vivência narrada é um processo de construção. 


\title{
O espaço/tempo da construção: a Liga de Segurança Alimentar e Nutricional
}

\author{
Nesta fase narrativa do texto sobre a LASAN, lembramos muito de Paulo Freire ${ }^{8}$, e sua fala o \\ representa: \\ uma das tarefas mais importantes da prática educativo-crítica é propiciar as condições em \\ que os educandos em suas relações uns com os outros e todos com o professor ou a \\ professora ensaiam a experiência profunda de assumir-se. Assumir-se como ser social e \\ histórico, como ser pensante, comunicante, transformador, criador, realizador de sonhos, \\ capaz de ter raiva porque capaz de amar. ${ }^{8}$
}

Importante contextualizar onde acontece esta vivência de formação, de emoções, de participação. Ela se dá no sul do estado do Rio de Janeiro no trecho inferior do médio vale do rio Paraíba do Sul, em um Centro Universitário da cidade de Volta Redonda. Falamos sobre o interior do estado, no entanto, o município é a terceira maior receita fiscal do estado, com uma população aproximada de trezentas mil pessoas.

Como toda instituição universitária, também é regida por normas instrucionais e legais, e este Centro Universitário define como ligas acadêmicas entidades sem fins lucrativos com duração ilimitada, criadas e organizadas por acadêmicos, professores e profissionais que apresentam interesses em comum. Constitui-se por atividade extraclasse e deve desenvolver ações voltadas para o ensino e para a educação ${ }^{9}$.

A Liga Acadêmica de Segurança Alimentar e Nutricional (LASAN), fundada em 2007, tem como característica ser entidade de natureza acadêmica, cujo objetivo principal é motivar os alunos a aprofundar o tema SAN, realizando atividades de ensino, pesquisa e extensão.

É a primeira Liga Acadêmica do Curso de Nutrição no Centro Universitário ao qual é vinculada, sendo pioneira, tanto pela temática abordada, quanto por ser, até então, a única liga acadêmica do país neste tema.

O percurso de sua fundação foi marcado por conversas iniciadas nas aulas da disciplina de Nutrição e Saúde Pública. Como parte dos objetivos propostos pela disciplina, o aluno entra em contato com o problema da fome no Brasil, sua caracterização, processo histórico relacionado ao modelo econômico do país, e a situação atual. A pauta inicial é a desigualdade social e a mudança do estado de fome clássico para o estado de fome oculta.

Nesta trajetória inclui-se Josué de Castro ${ }^{10}$ no cenário brasileiro, importante pesquisador não tanto em sua época, mas na atualidade, por suas concepções que nos norteiam até hoje. É notório o seu pioneirismo para a Nutrição, e suas pesquisas iniciais na década de 1940 alteraram o modelo paradigmático da fome e das suas causas reais, denunciando sua relação com vertentes econômicas e revelando sua existência e persistência num processo imposto pelo homem ao homem ${ }^{10}$.

O referido autor questiona o modelo de formação dos nutricionistas, e sugere que estes profissionais deveriam ser os principais responsáveis pelo combate à fome no Brasil.

Nos modos de fazer destas aprendizagens, busca-se desenvolver o senso crítico dos alunos utilizando metodologias participativas de caráter problematizador, aproveitando as possibilidades que a disciplina abre, mas entendendo suas limitações. Utilizam-se vídeos seguidos de conversas e debates incluindo dados nacionais importantes, como a questão da produção agrícola brasileira em contraposição à reticente condição de insegurança alimentar nacional e outros. Busca-se reflexão e a percepção dos alunos quanto às dimensões do problema da fome no Brasil. Conversas enriquecidas pelo encontro, segundo Certeau ${ }^{11}$, a arte de conversar:

as retóricas da conversa ordinária são práticas transformadoras de situações de palavra, de produções verbais onde o entrelaçamento das posições locutoras instaura um tecido oral sem proprietários individuais, as criações de uma comunicação que não pertence a ninguém. A conversa é um efeito provisório e coletivo de competências na arte de manipular lugares comuns e jogar com o inevitável dos acontecimentos para torná-los habitáveis. ${ }^{11}$ 
Estas questões fervilham nas mentes e nos corações de todos e motivam as discussões nas próximas aulas. Tratamos da formação em nutrição e, nela, não escapam as normas, diretrizes, grades, currículo, mas também se conectam com a proposta de Josué de Castro de que este profissional seja formado para resolver grandes problemas da fome do país. Discute-se se os modelos formativos respondem a exigência de um profissional generalista que atenda a várias atribuições e ações engajadas, com senso crítico e com ampla atuação em saúde pública. Lança-se, ao fim da aula, mais um desafio aos alunos, qual seja refletir sobre a pergunta: o que vocês, como futuros nutricionistas, têm a ver com o problema da fome no Brasil?

Nem sempre os alunos são tão domesticados a ponto de saírem das aulas sem continuidade dos diálogos. Criam outras maneiras de fazer, que sempre surpreendem os docentes. Novamente nos inspiramos em Certeau ${ }^{11}$; segundo ele são as táticas desviacionistas:

a tática é movimento dentro do campo de visão do inimigo, como dizia Büllow, e no espaço por ele controlado. Ela opera golpe por golpe, lance por lance. Aproveita ocasiões e delas depende, sem base para estocar benefícios, aumentar a propriedade e prever saídas. ${ }^{11}$

Após o fim da aula, o professor responsável foi procurado por um grupo de alunos, que se sentiram incomodados com os questionamentos e reflexões. Foram provocados, e no dizer deles, precisavam fazer algo como futuros profissionais, também foram estimulados a pensar sobre este "algo", e se possível relacioná-lo às necessidades locais. Marcaram outras conversas conjuntas para iniciar a tessitura deste modo de fazer refletido e renovado. Para isto precisavam de algum tempo para pensar, propor, construir e alinhavar alguns fios.

Antes do prazo proposto pelo professor, os alunos vieram acompanhados de outros da mesma turma, o grupo construiu outras redes e aumentou. Conversaram sobre uma série de possibilidades de atuação, porém sem uma organização possível que se convertesse em práticas concretas.

Este projeto não foi diferente de alguns projetos acadêmicos, nos quais, primeiramente, se pretende um projeto de cooperação internacional, depois, o reduzimos às instâncias nacionais, para chegar ao regional, passando às realidades estaduais, sucessivamente às municipais, para, somente depois, refletindo sobre a multiplicidade dos aspectos imbricados, chegar numa construção local. A ideia inicial dos alunos baseava-se na construção de uma organização sem fins lucrativos e atuando como uma organização não governamental.

Depois de conversas, argumentações, críticas, sugeriu-se aos alunos que pensassem na criação de uma Liga Acadêmica, um espaço institucional onde pudessem realizar atividades de ensino-pesquisa-extensão integradas e teriam a escuta e os apoios necessários para esta construção.

\section{O plano de voo e o percurso}

Trataremos um pouco sobre as ligas acadêmicas, destacando que são organizações mais comuns no campo da medicina, em diversas áreas.

A tradição das ligas acadêmicas se deu no Curso de Medicina para aprofundar um tema ou atender as demandas da população em áreas específicas. A importância destas organizações estaria em inserir os alunos na comunidade através de práticas educativas, desenvolvendo ações de saúde, ensino, pesquisa e extensão. Movimentos de práticas diferenciadas no cenário formal dos currículos do Curso em questão, uma proposta de currículo paralelo. Alguns movimentos são esperados em relação às ligas acadêmicas de medicina:

espera-se que as LA constituam-se "espaços" onde o aluno possa atuar junto à comunidade como agente de promoção de saúde e transformação social, ampliando o objeto da prática médica, reconhecendo as pessoas como atores do processo saúde-doença, o qual envolve aspectos psicossociais, culturais e ambientais, e não apenas biológicos. ${ }^{12}$ 
As Ligas podem contribuir para a formação profissional mais ampliada dos alunos de diferentes cursos da área da saúde extrapolando os limites das salas de aula. Acompanhamento e reflexão são necessários para que o processo de desenvolvimento das ligas acadêmicas não se torne acrítico e compactue com o ideário do assistencialismo.

Na opinião de Torres et al. ${ }^{12}$ é preciso avaliar a relevância social e acadêmica deste tipo de atividade para que não se bloqueiem as possibilidades de interação entre os alunos e as comunidades onde estão inseridos. Estas atividades são vivenciadas, mas são pouco sistematizadas e divulgadas. O autor também ressalta a dificuldade de encontrar referências sobre este tema.

Voltemos para as conversas entre professor e alunos sobre o percurso da construção da LASAN. Nos encontros foi esclarecida a necessidade de se proceder a formalidades para que a atividade fosse reconhecida no âmbito da academia; verificar o estatuto, as normas vigentes no Centro Universitário ao qual está vinculada, distribuição de cargos necessários à formação básica, a definição e disponibilidade de um professor orientador. Estes aspectos foram colocados em prática pelos alunos, e a LASAN instituída começa suas atividades junto ao Curso de Nutrição, tendo como docente responsável o professor da disciplina de Nutrição e Saúde Pública.

As primeiras atividades desenvolvidas pela LASAN são atividades de extensão e ensino, como o convite aos profissionais da área a proferirem palestras sobre diversos aspectos do tema SAN, abertos aos alunos do Curso, e com presença obrigatória dos alunos-membros da Liga. Com a divulgação das atividades da LASAN entre os alunos, mais alunos de outros períodos se interessam e o número de colaboradores da Liga aumenta.

Com o aumento de alunos-membros, poderiam pensar em atividades na realidade social do município. Tornou-se possível o desenvolvimento de atividades de apoio a entidades assistenciais que atuam com assistência alimentar. As estratégias são elaboradas e os alunos dividem-se em grupos, sob a orientação do docente responsável, na atuação em parceria com Organizações não governamentais. As atividades iniciais concentraram-se no treinamento dos voluntários das organizações, em segurança microbiológica no preparo de refeições, além de atividades educativas sobre alimentação saudável e sobre o Direito Humano à Alimentação Adequada (DHAA).

Neste meio tempo, o professor responsável pela LASAN entra em contato com parceiros na área de SAN, atores na esfera estadual e nacional. Compartilhando suas experiências e troca de informações, recebeu sugestões e um presente para a liga, que foi um vídeo sobre a vida de Josué de Castro. Uma nova atividade é estruturada: um vídeo-debate com os alunos membros, despertando o desejo de mostrar, aos demais estudantes do curso, a importância de Josué de Castro na formação do profissional nutricionista brasileiro.

A direção da Liga se articula e propõe a realização de um Movimento de resgate à memória de Josué de Castro, com a confecção de camisetas com o rosto do pesquisador com os dizeres: "Você conhece este homem?". Todos os alunos-membros e alguns professores recebem a camiseta e são orientados a usá-la ao menos uma vez por semana. Quando indagados sobre quem era o homem na camiseta, dariam uma explicação resumida sobre Josué de Castro e seu papel para o Brasil e para a profissão de nutricionista. Este movimento teve a duração de, pelo menos, seis meses.

Outras parcerias se firmaram e novos eventos surgiram, como a participação da direção da LASAN em evento estadual ligado ao tema, fomentando nos alunos a vontade de realizar um evento próprio, que se concretizou em 2008. O evento foi denominado de I Seminário de Segurança Alimentar e Nutricional vinculado ao Centro Universitário. A proposta seria debater os desafios e avanços do tema na região, com participação de profissionais experientes na área; agentes governamentais e não governamentais militantes no tema, e destacar experiências bem-sucedidas no campo da SAN, assim como desenvolver novos meios de atuação para a LASAN.

Além do apoio institucional do Centro Universitário, teve como parceiros: o Conselho Estadual de Segurança Alimentar e Nutricional (Consea/RJ); a Associação Brasileira de Direitos Humanos (ABRANDH); o Ministério de Desenvolvimento Social e Combate a Fome (MDS); o Banco de Alimentos de Volta Redonda e Conselhos de Segurança Alimentar de Volta Redonda e de Piraí. Houve participação expressiva de estudantes de graduação, nutricionistas, e representantes de entidades da sociedade civil de toda a região do Médio-Paraíba. No local do evento, foi organizada uma exposição sobre Josué de 
Castro, gentilmente cedida pelo Conselho Estadual de Segurança Alimentar e Nutricional/RJ (Consea/

RJ) e Conselho Regional de Nutricionistas - $4^{\text {a }}$ Região e, posteriormente, doada à LASAN.

As atividades de extensão locais, o impacto causado pelo evento e a divulgação das atividades da Liga pelas entidades assistenciais trouxeram novos voos e desafios. A LASAN recebe convite para desenvolver eventos e parcerias fora do município, fora dos muros acadêmicos e com envolvimento de vários estudantes do Curso de Nutrição.

Podemos citar o I Encontro de Estudantes em Segurança Alimentar e Nutricional e a participação da LASAN em atividade da Rede de Educação Cidadã do Rio de Janeiro, em conjunto com a Associação de Pequenos Produtores de Cachoeira Grande, do bairro de Piabetá, em Magé, no estado do Rio de Janeiro. Esta última com objetivo de realizar levantamento dos moradores, suas dificuldades e potencialidades relacionadas à produção agrícola, para orientar as ações a serem desenvolvidas.

O I Encontro dos Estudantes e Segurança Alimentar e Nutricional teve como objetivo comemorar o centenário do nascimento de Josué de Castro e divulgar a experiência da LASAN para Instituições de Ensino Superior do estado do Rio de Janeiro, e contou com a presença de Ana Maria de Castro, filha de Josué de Castro.

Com o reconhecimento e relevância das atividades da LASAN, esta foi convidada a ter assento como membro titular no Consea/RJ, representando o movimento discente de Nutrição, e o professor orientador como membro suplente deste Conselho.

A participação dos membros da LASAN intensa e renovadora, motiva a tessitura de nós integradores com os movimentos sociais do município e culmina no convite para participar da organização da $3^{a}$ Conferência Municipal de Segurança Alimentar e Nutricional de Volta Redonda, realizada em julho de 2011. Outro passo importante foi indicação como entidade delegada para representar o município na Conferência Estadual de Segurança Alimentar e Nutricional do Rio de Janeiro em agosto de 2011.

A relevância da atuação da LASAN no movimento de construção do DHAA no município de Volta Redonda é reconhecida pela tomada de assento no Conselho Municipal de Segurança Alimentar e Nutricional.

Atualmente, a LASAN encontra-se em sua quarta diretoria, e mantém-se ativa nas parcerias com as organizações não governamentais do município, além das ações de promoção de SAN em escolas da rede pública de ensino. Estas atuações acontecem no próprio município e também no município de Pinheiral. Os limites se expandem com o desenvolvimento de pesquisas sobre segurança alimentar no distrito de Arrozal, no município de Piraí.

A atuação da LASAN continua enredando em seus fios novos parceiros discentes, encantados pela repercussão das atividades, pela possibilidade de vivenciar as redes de saberes do tema e pela rara oportunidade de aprenderensinar entre os próprios discentes do curso de nutrição.

\section{Para terminar as conversas, concluindo e provocando, tudo ao mesmo tempo enredado}

A experiência aqui narrada possibilita ampliar processos de tessitura, articulação, integração e recriação de saberes sobre SAN. Estimula a reflexão sobre a formação em nutrição não só sobre o ponto de vista dos conteúdos e diretrizes prescritos nos currículos planejados, mas na necessidade de romper com os muros que separam o pensar e o fazer. Parece lugar comum esta afirmativa, mas a história se repete e os saltos qualitativos não são significativos, dificultando as tramas dos conhecimentos dentro e fora da universidade. $\mathrm{O}$ avanço nas reflexões e ações unindo práticateoriaprática seria ousar para além da possível hierarquia nestes momentos pedagógicos.

Esta experiência promove e provoca uma reflexão crítica da formação que desempenhamos, considerando dúvidas, incertezas, mas também desejos atuais de modos de fazer diferentes, com o olhar no futuro. "Nossas práticas podem ser suporte importante para as mudanças que queremos" ${ }^{13}$. Com aprendizados diferenciados abrimos horizontes para a formação engajada e de relevância social. Vislumbra-se a diferença entre informar e formar, o ato transformado em diálogo permanente com as transformações da sociedade e a realidade local, tramando fios da rede de conhecimentos tecida em 
conjunto com universidade e comunidade e que extrapole permanentemente para seu exterior, o quanto possa, para criar novos fios e nós articulados.

Barros ${ }^{13}$ nos dá algumas pistas para os processos de formação: minimizar o sentido dicotômico de teoria/prática; competência técnica/domínio da prática; formação teórica/técnica; separação entre teoria, prática e compromisso político. Para tal transformação sugere a autora uma "política de invenção" ${ }^{13}$, onde se assuma uma postura ético-política e dialógica dos diferentes saberes, entendendo suas formas singulares, que amplie cada vez mais as possibilidades de experimentação e que saiba lidar com a imprevisibilidade do cotidiano.

A formação como processo em construção unindo conhecimento teórico e prática como exercício da profissão enreda fios comuns de aprendizado, facilita transformar vivências em caminhos de experiência, num esforço de respeito à autonomia e à identidade dos educandos. Por outro lado, assumir o conhecimento como acabado e definitivo propicia a criação de barreiras, afastando as bonitezas de conhecer o mundo ${ }^{8}$, desconsidera outras presenças e outras experiências, esteriliza o diálogo aberto, imaginativo e curioso entre professores, alunos e pessoas do mundo. Formar exige respeito aos saberes múltiplos, ética em pensamentos e ações, risco e aceitação ao que é e não é conhecido, crítica à prática e compromisso.

Esta vivência acredita no emaranhado das múltiplas facetas que envolvem o tema da SAN, evidenciando que podemos ir além dos encontros intersetoriais e vislumbrar caminhos que promovam diálogo fluido e relevante, recriando os modos de fazer e deixar-se surpreender na descoberta que "a riqueza de entrar na rede é que cada um pode escolher ou mesmo dar um nó, e quanto mais nós mais surpresas. E se aprender não é surpreender então o que seria?" 14.

As atividades da LASAN e orientadas pelo professor, não têm a pretensão de suprir ou substituir as ações dos governos locais, que necessitam implementar um conjunto de políticas públicas e monitorá-las.

Estas vivências contribuem para o processo de formação engajado, unindo técnico e político, e como prática social, na forma de inserção criativa dos discentes na realidade local e na tessitura de redes de conhecimento que contribuirão para atitudes solidárias, para o exercício participativo, e autonomia profissional. O fazer diferenciado pode contribuir, como nos diz Lowy ${ }^{15}$, para a construção de "uma cultura da esperança voltada para a perspectiva de um futuro emancipador".

\section{Colaboradores}

Os autores trabalharam juntos em todas as etapas de produção do manuscrito.

\section{Referências}

1. Oliveira IB, organizador. Narrativas: outros conhecimentos, outras formas de expressão. Rio de Janeiro: Faperj; 2010.

2. Oliveira IB, Geraldi W. Narrativas: outros conhecimentos. In: Oliveira IB, organizador. Narrativas: outros conhecimentos, outras formas de expressão. Rio de Janeiro: Faperj; 2010. p.13-28.

3. Conselho Nacional de Segurança Alimentar e Nutricional (CONSEA). Princípios e diretrizes de uma Política de Segurança Alimentar e Nutricional. Textos de Referência da II Conferência Nacional de Segurança Alimentar e Nutricional. Brasília, DF: Gráfica e Editora Positiva; 2004. 
4. Alves N, organizador. Criar currículo no cotidiano. São Paulo: Cortez; 2002 (Série Cultura Memória e Currículo, v.1).

5. Burlandy L. A construção da política de segurança alimentar e nutricional no Brasil: estratégias e desafios para a promoção da intersetorialidade no âmbito federal de governo. Cienc Saude Colet. 2009; 14(3):841-60.

6. Gallo $S$. Transversalidade e educação: pensando uma educação não-disciplinar. In: Alves N, Garcia RL, organizadores. O sentido da escola. Rio de Janeiro: DP\&A; 1999. p.17-41.

7. Santos BS, Meneses MPG, Nunes JA. Introdução: para ampliar o cânone da ciência: a diversidade epistemológica do mundo. In: Santos BS, Meneses MPG, Nunes JA, organizadores. Semear outras soluções: os caminhos da biodiversidade e dos conhecimentos rivais. Rio de Janeiro: Civilização Brasileira; 2005. p.21-121.

8. Freire P. Pedagogia da autonomia: saberes necessários à prática educativa. São Paulo: Paz e Terra; 2011.

9. Centro Universitário de Volta Redonda - UniFOA [internet]. Ligas Acadêmicas [acesso 2012 Ago 15]. Disponível em: http://www.foa.org.br/portal_ext/liga_acad/ default.asp

10. Castro J. Geografia da fome, o dilema brasileiro: pão ou aço. 14.ed. Rio de Janeiro: Civilização Brasileira; 2001.

11. Certeau M. A invenção do cotidiano: artes de fazer. Petrópolis: Vozes; 1994.

12. Torres AR, Oliveira GM, Yamamoto FM, Lima MCP. Ligas Acadêmicas e formação médica: contribuições e desafios. Interface (Botucatu). 2008; 12(27):713-20.

13. Barros MEB. Desafios ético-políticos para a formação dos profissionais de saúde. In: Pinheiro R, Ceccim RB, Mattos RA, organizadores. Ensinar saúde: a integralidade e o SUS nos cursos de graduação na área da saúde. Rio de Janeiro: Cepesc, IMS/UERJ, Abrasco; 2011. p.131-50

14. Garcia RL. Atravessando fronteiras e descobrindo (mais uma vez) a complexidade do mundo. In: Alves N, Garcia RL, organizadores. O sentido da escola. Rio de Janeiro: DP\&A; 1999. p.81-110

15. Lövy M. Por uma cultura da solidariedade e da esperança. In: Moraes $D$, organizador. Combates e utopias. Rio de Janeiro: Record; 2004. p.373-6.

\section{Errata}

Na página 187, onde se lia: Olívia Maria Oliveira Schneider o correto é: Olívia Maria Ferreira Schneider

Nas páginas 189, 191, 193 e 195, onde se lia: Schneider OMO o correto é: Schneider OMF 
O presente artigo narra a trajetória da Liga Acadêmica de Segurança Alimentar e Nutricional (LASAN). Iniciativa pioneira de vivências práticas e discussões aprofundadas no tema segurança alimentar e nutricional. Surgiu como resposta aos desafios propostos em sala de aula sobre os modos de fazer a nutrição incluindo a responsabilidade da promoção do Direito Humano à Alimentação Adequada. Esta narrativa aborda a rede de temas sobre formação em nutrição e segurança alimentar e nutricional. Referencia-se nos conhecimentos de autores que debatem a formação e a educação crítica como prática social. A trajetória da LASAN aponta para caminhos renovados onde se podem transformar em ação os saberes relevantes em SAN, assim como experimentar renovadas formas de aprenderensinar Nutrição.

Palavras-chave: Educação superior. Nutrição. Segurança alimentar e nutricional. Liga acadêmica.

Conversations about buildingforming nutrition: the experiences and paths of food and nutrition security

This paper describes the history of the Academic League for Food and Nutrition Security (ALFNS). It was a pioneer initiative of practical experiences and deep discussions about food and nutrition security. Appeared as an answer to challenges proposed inside the classrooms that pointed out the need of building nutrition including responsibility of Human Rights to Proper Nourishment promotion. This narration approaches a network of themes related to nutrition and food security education. The present work makes references to the knowledge of authors that debate critical education as a social practice. The history of the Academic League for Food and Nutrition Security (ALFNS) points out to a new pathway, where relevant knowledge on Food and Nutrition Security turns into action, as well as experimenting new ways of learning teaching nutrition.

Keywords: College education. Nutrition. Food and nutrition security. Academic league.

\section{Conversaciones sobre formarhacer la nutrición: las vivencias y rutas de la Confederación de la Seguridad Alimentar y Nutricional}

El presente artículo relata el trayecto de la Confederación Académica de Seguridad Alimentar y Nutricional (LASAN en la abreviación latina). Proyecto pionero de vivencias prácticas y discussiones aprofundizadas en el tema seguridad alimentar y nutricional. Surgió como respuesta a los desafíos propuestos en classes, sobre las maneras de hacer la nutrición, incluyendo la responsabilidad de la promoción del Derecho Humano a Alimentación Adecuada. Esta narrativa trata de uma serie de temas sobre formación en nutrición y seguridad alimentar y nutricional. Basada en los conocimientos de los autores que discuten la formación y la educación critica como práctica social. La trayectoria de LASAN apunta para caminos renovadores donde se puede cambiar por acciones los relevantes saberes en Seguridad Alimentar y Nutricional, así como experimentar nuevas maneras de aprenderenseñar nutrición.

Palabras clave: Educación superior. Nutrición. Seguridad alimentar y nutricional. Confederación académica. 